Am. J. Trop. Med. Hyg., 64(1, 2), 2001, pp. 12-19

Copyright $(\mathcal{C} 2001$ by The American Society of Tropical Medicine and Hygiene

\title{
MULTIPLE GENOTYPES OF ST. LOUIS ENCEPHALITIS VIRUS (FLAVIVIRIDAE: FLAVIVIRUS) CIRCULATE IN HARRIS COUNTY, TEXAS
}

\author{
LAURA J. CHANDLER, RAY PARSONS, AND YVONNE RANDLE \\ University of Texas Medical Branch, World Health Organization Collaborating Center for Tropical Diseases, Galveston, Texas; \\ Harris County Mosquito Control Division, Houston, Texas
}

\begin{abstract}
St. Louis encephalitis (SLE) is endemic in Harris County, Texas. The disease is a public health concern in Houston, the largest city in Harris County, and in the state. Consequently, intensive surveillance for SLE virus in local mosquito populations is carried out by the Harris County Mosquito Control Division each year. In this study, we examined genetic variation among SLE isolates obtained during routine virus surveillance over a 13-year time period (1986-1999). St. Louis encephalitis virus isolates were tested for genetic variation using reverse transcriptionpolymerase chain reaction followed by single-strand conformation polymorphism (SSCP). The results indicated that multiple genotypes of the virus circulate in Harris County. During several years, the genotypes were restricted in their location, i.e., each general area within the county had a specific genotype of the virus. In other years, the various genotypes were widely distributed throughout the county. The presence of multiple distinct genotypes suggests that viruses with different biological characteristics may be circulating in Harris County, and that discrete foci of SLE virus activity occur simultaneously.
\end{abstract}

\section{INTRODUCTION}

St. Louis encephalitis (SLE) is a mosquito-borne viral disease of humans. The causative agent, SLE virus, is a member of the family Flaviviridae, in the genus Flavivirus. St. Louis encephalitis virus is widely distributed throughout the United States and cases of the disease are reported annually. St. Louis encephalitis occurs in both endemic and epidemic forms. ${ }^{1,2}$ St. Louis encephalitis is considered to be an important public health problem in many parts of the United States, especially the southern states, where transmission of the virus occurs regularly and cases of the disease occur annually despite the presence of active surveillance and mosquito control programs in many areas.

In Texas, SLE cases occur almost every year, and the disease is a regular public health concern. As of 1996, Texas has reported a total of 964 cases of SLE, the largest of any state in the United States. While SLE is a health concern throughout the state, it is especially important in major urban areas such as Houston (located in Harris County), Dallas, and Corpus Christi, which have all experienced large epidemics. $^{3-5}$ Since the 1960 s, Harris County has reported more SLE cases than any other county in the nation. ${ }^{6}$

SLE was first noted in Harris County in 1964 during a large epidemic in the Houston metropolitan area., ${ }^{5,7}$ Retrospective serological studies done following this epidemic suggested that Houston was probably free of SLE prior to $1964 .^{8}$ Following the 1964 epidemic, the Harris County Mosquito Control Division was established for the purpose of monitoring SLE virus activity, as well as controlling the mosquito vectors. ${ }^{9}$ Since that time, an extensive surveillance program for SLE activity in bird and mosquito (Culex quinquefasciatus) populations has been maintained on a yearly basis. The surveillance program includes serological monitoring of birds and collection of vector mosquitoes for virus isolation. Surveillance data collected during the past 36 years have shown that SLE virus is endemic in Harris County (Table 1), and that most cases of the disease occur during the summer months. Serological monitoring of birds has shown that house sparrows are the most commonly infected vertebrate hosts of SLE in Houston. ${ }^{10}$
The level of SLE activity in Harris County varies from year to year. As in many other areas of the United States, transmission of the virus is endemic, with intermittent epidemics. Attack rates and case fatality rates vary between epidemics. ${ }^{9}$ During some years, SLE virus transmission is focal, with isolates being obtained only from limited areas; in other years, the virus is widespread and found throughout the county (Harris County Mosquito Control Division, unpublished data). For example, the 1964 epidemic was limited to a small area in central Houston; while in 1976, cases occurred throughout the county. ${ }^{9}$ Although SLE virus is isolated from Harris County during most years, in occasional years, no activity is detected, and no virus is isolated from mosquito pools (Table 1). The mechanism(s) of virus persistence during these "silent" periods, as well as overwintering, are not known.

Epidemiological and experimental evidence has shown that SLE virus strains with distinct biological differences circulate in the United States. ${ }^{1}$ St. Louis encephalitis strains have been identified that differ in several phenotypic characteristics that may impact transmission and disease potential of the virus, including neurovirulence, ability to cause viremia in birds, and mosquito infectivity. ${ }^{11-13}$ Genetic studies using oligonucleotide fingerprinting (ONF) demonstrated that viremia levels and neurovirulence correlated strongly with ONF patterns and with geographic origin of the SLE virus strains. ${ }^{12}$ These studies demonstrated that some genotypes were more virulent in animals, and that specific genotypes were associated with epidemic transmission. A molecular epidemiologic study of SLE virus in California revealed that multiple strains of the virus circulate in that state. This study indicated that new genotypes of the virus were either introduced or emerged due to genetic changes. ${ }^{14}$

Molecular techniques are increasingly being used in studies of arboviral epidemiology. Molecular studies can identify genetic characteristics of a virus that may influence its epidemiology, virulence, and other biological characteristics. Information about the genetic characteristics of pathogens can also be used to identify the source of epidemics. While studies of this type have been used to examine strain variation among SLE isolates from diverse geographic are- 
TABLE 1

St. Louis encephalitis (SLE) surveillance data from Harris County, Texas 1975-1999

\begin{tabular}{ccccc}
\hline Year & $\begin{array}{c}\text { No. of mosquito } \\
\text { pools tested }\end{array}$ & $\begin{array}{c}\text { No. of SLE } \\
\text { virus isolates }\end{array}$ & $\begin{array}{c}\text { No. of reported } \\
\text { human cases }\end{array}$ & No. of deaths \\
\hline 1975 & 604 & 5 & 34 & 2 \\
1976 & 1,541 & 35 & 28 & 2 \\
1977 & 1,314 & 2 & 3 & 0 \\
1978 & 880 & 0 & 0 & 0 \\
1979 & 928 & 0 & 0 & 0 \\
1980 & 1,093 & 36 & 53 & 1 \\
1981 & 1,463 & 1 & 1 & 1 \\
1982 & 2,447 & 33 & 7 & 1 \\
1983 & 4,045 & 23 & 0 & 0 \\
1984 & 3,682 & 0 & 0 & 0 \\
1985 & 2,448 & 0 & 0 & 0 \\
1986 & 5,915 & 106 & 26 & 3 \\
1987 & 3,374 & 0 & 0 & 0 \\
1988 & 3,374 & 0 & 0 & 0 \\
1989 & 7,216 & 24 & 4 & 1 \\
1990 & 6,561 & 44 & 24 & 6 \\
1991 & 6,101 & 89 & 41 & 6 \\
1992 & 7,356 & 65 & 9 & 1 \\
1993 & 7,419 & 35 & 1 & 0 \\
1994 & 4,873 & 38 & 0 & 0 \\
1995 & 5,140 & 0 & 0 & 0 \\
1996 & 5,242 & 20 & 2 & 0 \\
1997 & 4,170 & 0 & 0 & 0 \\
1998 & 5,154 & 40 & 4 & 0 \\
1999 & 3,838 & 0 & 0 & 0 \\
Total & 96,178 & 596 & 237 & 24 \\
\hline & & & &
\end{tabular}

as, ${ }^{12,14,15}$ no study of SLE isolates from a single geographic area over an extended period of time has been done before. In this report, the genetic variability of SLE isolates obtained during routine surveillance from Harris County, Texas, was examined. Using molecular analyses, we demonstrate here that multiple genotypes of SLE virus circulate within a limited geographic area during a single year.

\section{MATERIALS AND METHODS}

Virus isolates. Prototype SLE virus (Parton strain), originally isolated in St. Louis, Missouri, in 1933 was obtained from the Arbovirus Reference Center at the University of Texas Medical Branch. This virus had been passaged 16 times in mice and once Vero cells. The remaining SLE virus strains were isolated during the SLE Surveillance Program of the Harris County Mosquito Control Division. All of the Harris County isolates were examined after initial isolation in Vero cell culture, duck embryo cell culture (DECC), or suckling mouse brain.

Mosquito collections. Mosquitoes were collected as part of the routine SLE Surveillance Program carried out by the Harris County Mosquito Control Division. All isolates were made from female Culex quinquefasciatus mosquito pools collected during the years 1986-1999. Methods used for the collection, selection, and processing of mosquitoes have been described previously. ${ }^{16}$ Mosquitoes were collected from 248 sites in Harris County during the transmission season (May through November), and only adult female $C x$. quinquefasciatus used for virus isolation. A map of Harris County illustrating the collection locations is presented in Figure 1. The numbers on this map represent the 248 sites that are collected on a regular basis in Harris County. This system is also used for monitoring mosquito populations and for mosquito control purposes. Mosquito trapping begins in Week 13 of each year with collections in the central portion of the county (inside the inner loop, Figure 1). Additional sites are added weekly, and by Week 24, mosquitoes are collected from all 248 areas of the county on a weekly basis. Surveillance continues until the end of November each year. For the purposes of this study, major geographical regions (north, southeast, etc.) in the county were defined based on the location of the highways that traverse Harris County (Figure 1).

Virus isolation procedure. Mosquito pools were initially screened for SLE virus by antigen-capture ELISA. ${ }^{17}$ Enzymelinked immunosorbent assay-positive pools were subsequently processed for virus isolation in tissue culture (Vero and DECC) and suckling mice. ${ }^{16}$ Isolates were confirmed as SLE virus by the complement fixation test. Following isolation of virus, a stock of each isolate was prepared. Stocks were stored at $-70^{\circ} \mathrm{C}$ until the time of RNA extraction. The use of unpassaged viruses in this study eliminated the potential for genetic variation due to multiple passages in the laboratory.

Viral RNA extraction. The titer of virus in the stock preparations was $10^{6}-10^{8}$ plaque forming units per mL. RNA was extracted from stock virus preparations using Trizol LS reagent (Gibco-BRL, Gaithersburg, MD), following the manufacturer's instructions. In pilot experiments, the sensitivity of the RT-PCR was previously determined to be approximately 100 plaque forming units (PFU) of virus, thus at least $200 \mu \mathrm{L}$ of material was subjected to RNA extraction, giving adequate levels of RNA to detect using the PCR technique. RNA was restored in $50 \mu \mathrm{L}$ of sterile, nuclease-free water.

RT-PCR. Two primers (F880 and B1629) designed to amplify a 750-bp portion of the envelope gene of the virus were used in this study. These primers had been previously demonstrated to be specific for SLE virus, detecting all geographic strains of the virus, including strains from outside the United States. ${ }^{18}$ The sequence of the forward primer (F880) is $5^{\prime}$-GATTGGATGGATGCTAGGTAG-3'. This primer represents bases 880-901 on the genomic RNA and is positive-sense. The reverse primer, B1629, represents bases $1,608-1,629$, is negative-sense, and the sequence is $5^{\prime}$ GGTTCAAGTCGTGAAACCAGTC-3'. RT-PCR was carried out as previously described. ${ }^{18}$

SSCP analysis. Following PCR, the single-strand conformation polymorphism (SSCP) technique ${ }^{18}$ was used to test virus isolates for genetic variation. Single-strand conformation polymorphism is based on the electrophoretic mobility of single-stranded DNA molecules in nondenaturing acrylamide gels. When double-stranded DNA is denatured by heating, then rapidly cooled to prevent double-strand reannealing, intra-strand base pairing within the single strands occurs, allowing secondary structures to form. The conformation of these structures is dependent on the primary sequence of the DNA. DNA molecules with differences between their primary sequences will show polymorphic banding patterns when electrophoresed in nondenaturing gels. The presence of multiple bands on the gels indicates that several different conformations can be formed when the samples are cooled during the SSCP procedure. The sensitivity of SSCP for detecting single nucleotide changes in 


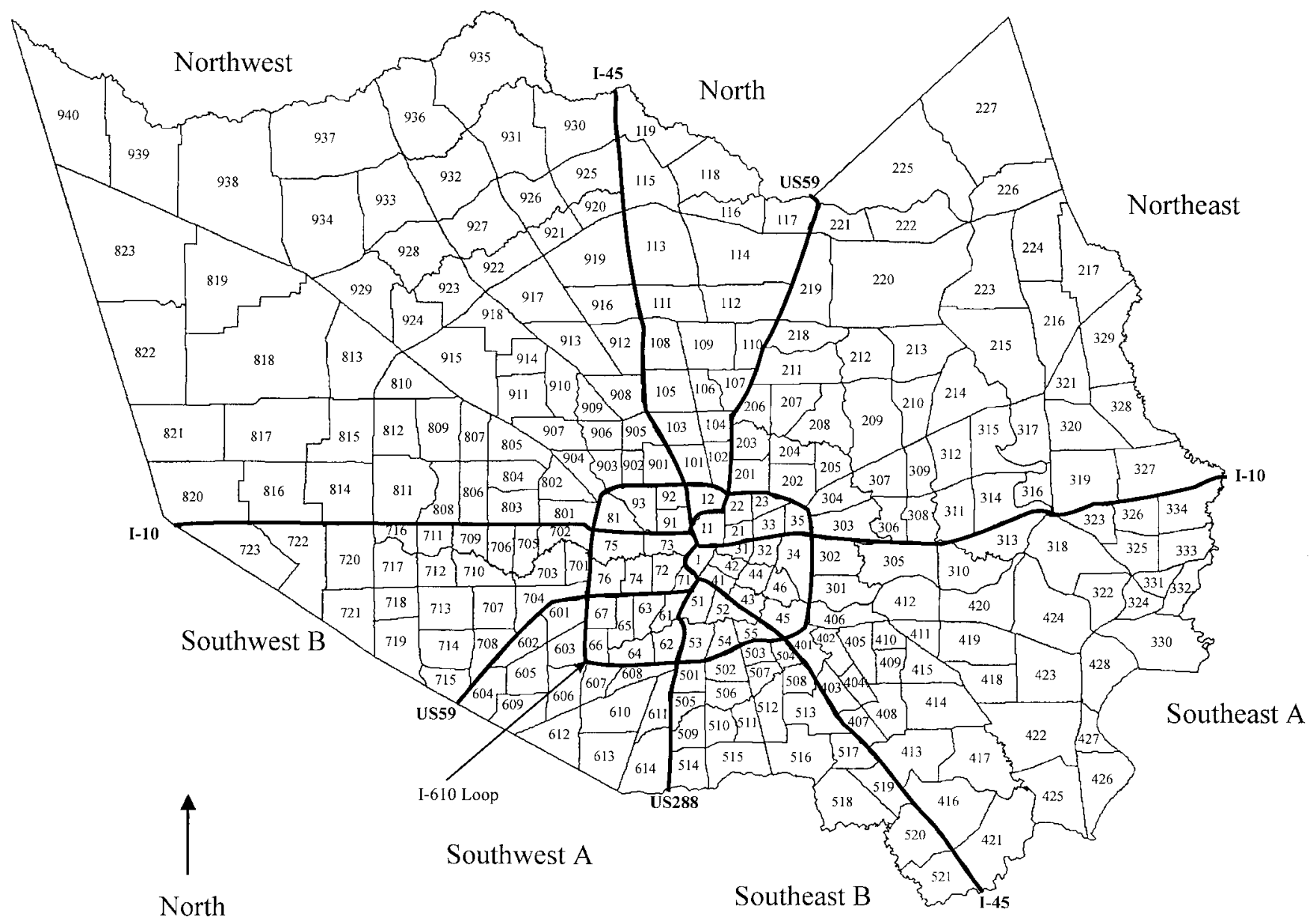

FIGURE 1. Area map of Harris County, Texas. Each numbered area corresponds to the location of a mosquito collection site. The major highways that traverse Harris County are identified as bold lines. The county was divided into major geographic areas (central, northwest, north, northeast, southeast A and B, and southwest A and B). The major areas were based on the highways that traverse Harris County.

SLE virus was previously demonstrated. ${ }^{18}$ For SSCP analysis, $150 \mathrm{ng}$ of DNA obtained from the PCR reaction was mixed with $12 \mu \mathrm{L}$ of SSCP loading buffer (95\% formamide, $0.05 \%$ xylene cyanol, $0.05 \%$ bromophenol blue). The mixture was heated to $95^{\circ} \mathrm{C}$ and held for $5 \mathrm{~min}$, then quickly cooled in ice. Samples were immediately loaded onto an $8 \%$ polyacrylamide gel in tris-borate-EDTA (TBE) buffer, and electrophoresed at $9 \mathrm{mAmps}$ for $20.5 \mathrm{hr}$. Following electrophoresis, the gel was fixed for $30 \mathrm{~min}$ in $10 \%$ acetic acid, then silver stained. ${ }^{18}$ Migration of the bands was measured for each sample. Single-strand conformation polymorphism genotypes were assigned letters (A, B, C, etc.), based on the pattern of migration in the gel. The letters were assigned consecutively from year to year, beginning with 1986.

Statistical analyses. Statistical analyses using Kendall's rank correlation coefficient were performed. These analyses were used to examine the relationships between the intensity of mosquito sampling, number of SLE isolates obtained, number of isolates tested by SSCP, and number of genotypes obtained each year.

\section{RESULTS}

Virus isolations. St. Louis encephalitis virus was isolated during nine years between 1986-1998: 1986, 1989, 1990_
1994, 1996, and 1998 (Table 1). There was a positive relationship between the number of isolates made each year and the number of mosquito pools tested (correlation coefficient $=0.34 ; P=0.02$ ). Thus, in the years when no or few SLE isolates were obtained, the lack of virus isolation may have been attributed to an inadequate number of pools tested, not due to the true lack of virus circulation.

Genetic variation among the SLE isolates circulating in Harris County. Not all of the isolates were available for use in this study. Some of the older isolates had not been saved, and thus were no longer available; the total number of isolates available for testing in this study was 323. All of the isolates $(\mathrm{n}=323)$ that were identified as SLE virus by CF testing were successfully amplified by RT-PCR in this study. The SSCP analysis demonstrated that genetic heterogeneity exists among the SLE viruses circulating in Harris County. Multiple genotypes of the virus were seen among the isolates from almost every year (Tables 2 and 3). After examining isolates from all nine years, a total of 29 distinct genotypes of the virus were identified (Table 3 ). In one year (1993) only a single genotype of virus was detected. During most years, one or two genotypes predominated, and the remaining genotypes were found in fewer numbers. The SSCP analysis of all 40 SLE isolates made during 1998 is presented in Figure 2. 
TABLE 2

Summary of St. Louis encephalitis (SLE) virus genotypes from Harris County, Texas identified by single-strand polymorphism (SSCP) analysis

\begin{tabular}{cccc}
\hline Year & $\begin{array}{c}\text { Total no. of } \\
\text { SLE isolates }\end{array}$ & $\begin{array}{c}\text { No. tested } \\
\text { by SSCP }\end{array}$ & $\begin{array}{c}\text { No. of genotypes } \\
\text { circulating during } \\
\text { year }\end{array}$ \\
\hline 1986 & 106 & 28 & 4 \\
1989 & 24 & 24 & 2 \\
1990 & 44 & 35 & 7 \\
1991 & 89 & 81 & 6 \\
1992 & 65 & 50 & 4 \\
1993 & 35 & 16 & 1 \\
1994 & 38 & 34 & 3 \\
1996 & 20 & 15 & 3 \\
1998 & 40 & 40 & 4 \\
Total & 461 & 323 & \\
\hline
\end{tabular}

There was a positive relationship between the number of specimens tested by SSCP and the number of genotypes detected (correlation coefficient $=0.59 ; P=0.03$ ). There was also a strong relationship between the number of genotypes detected and the number of SLE isolates in any year (correlation coefficient $=0.53 ; P=0.05$ ). These results indicate that the genetic variation seen in some years may have simply been due to the large number of isolates obtained. However, it also indicates that when viral transmission and circulation is high, there is an increased opportunity for genetic variation to occur.

Geographic distribution of genotypes. To determine the geographic distribution of SLE virus strains, the genotypes were mapped to the location of the trap sites where the infected mosquitoes were collected. The geographic locations of SSCP genotypes varied from year to year (Table 3). In two years (1990 and 1994) the genotypes were closely correlated with geographic location. A map showing the distribution of genotypes in 1990 is presented in Figure 3A. In other years, no obvious geographic correlation was seen; genotypes were found in multiple areas and were widely distributed throughout the county. A map illustrating the distribution of genotypes in 1992 is presented in Figure 3B.

Temporal distribution of genotypes. To determine if genotypes remained stable, all of the genotypes were tested by SSCP simultaneously. The majority of the genotypes were only found during a single year (Figure 4). One genotype (E) was found in multiple years $(1989,1991,1992,1994$, 1996, and 1998). This conserved genotype was found in central Houston in 1989, 1991, and 1992, while by 1994, 1996, and 1998, it was found more widely distributed throughout the county (Table 4). This genotype (E) was not always the predominant strain. In 1991, 1992, 1994, and 1998, genotype E represented only a small minority of the strains identified. These results indicated that although one genotype was stable in Harris County, the SLE virus strains circulating in Harris County were continually undergoing genetic evolution.

\section{DISCUSSION}

Harris County provided an ideal location to study SLE in a single limited geographic area because of the active surveillance program and the presence of the virus during most years. Single-strand conformation polymorphism analysis of SLE virus strains isolated in Harris County during 13 consecutive years of surveillance indicated that multiple genotypes of the virus circulate simultaneously. With the exception of 1993, when only a single genotype of virus was found, from two to eight genotypes were identified each year. The presence of several genetic types within the city limits of Houston indicates that more than one strain of the virus is circulating, and supports previous observations made by the Harris County Mosquito Control Division demonstrating antigenic and biological differences among SLE isolates (unpublished data). Statistical testing using Kendall's rank correlation coefficient demonstrated a positive relationship between the number of isolates made each year and the number of mosquito pools tested (coefficient $=0.34, P=0.02$ ). This implies that the lack of virus isolation in certain years may have been attributed to an inadequate number of pools tested, not due to the true lack of virus circulation. However, it is important to note that the number of pools tested is a reflection of mosquito populations; in years when mosquito populations are low, fewer pools are collected and tested. These results indicate that mosquito populations can have a strong effect on circulation of virus.

The SSCP technique has recently been used to identify genetic variation in several types of RNA viruses, including arboviruses. Because the SSCP has been demonstrated to be an effective tool in molecular epidemiology studies, it was used in this study to rapidly and sensitively detect genetic variation among isolates of SLE virus in Harris County. In a previous study, the SSCP was demonstrated to be a rapid, easily performed, and sensitive technique for detection of genetic variation among SLE virus strains. ${ }^{18}$ The SSCP was capable of detecting 1-5 nucleotide base changes within

TABLE 3

Summary of geographic locations of St. Louis encephalitis (SLE) genotypes isolated in Harris County, Texas

\begin{tabular}{cll}
\hline Year & \multicolumn{1}{c}{ Genotype present } & \multicolumn{1}{c}{ Locations* } \\
\hline 1986 & A, B, C, D & Baytown, Northeast, Central \\
1989 & E, F & Central \\
1990 & G, H, I, J, K, L, M & Baytown, Central, Southeast, North, Northwest \\
1991 & E, N, O, P, Q, R & Central, Southeast A, Southeast B, Southwest A North, Northeast, Northwest, \\
1992 & E, S, T, U & Central, Northwest, Baytown, Southwest A \\
1993 & V & Central, Southeast B, Southwest B \\
1994 & E, W, X & Central, Southeast A \\
1996 & E, Y, Z & Central, Southeast A, Southwest A, North, Northwest \\
1998 & E, A', B', C' & Central, Southeast A, Southeast B, Southwest A, Northwest \\
\hline
\end{tabular}

* Refers to the general location within Harris County, corresponding to Figure 1. 


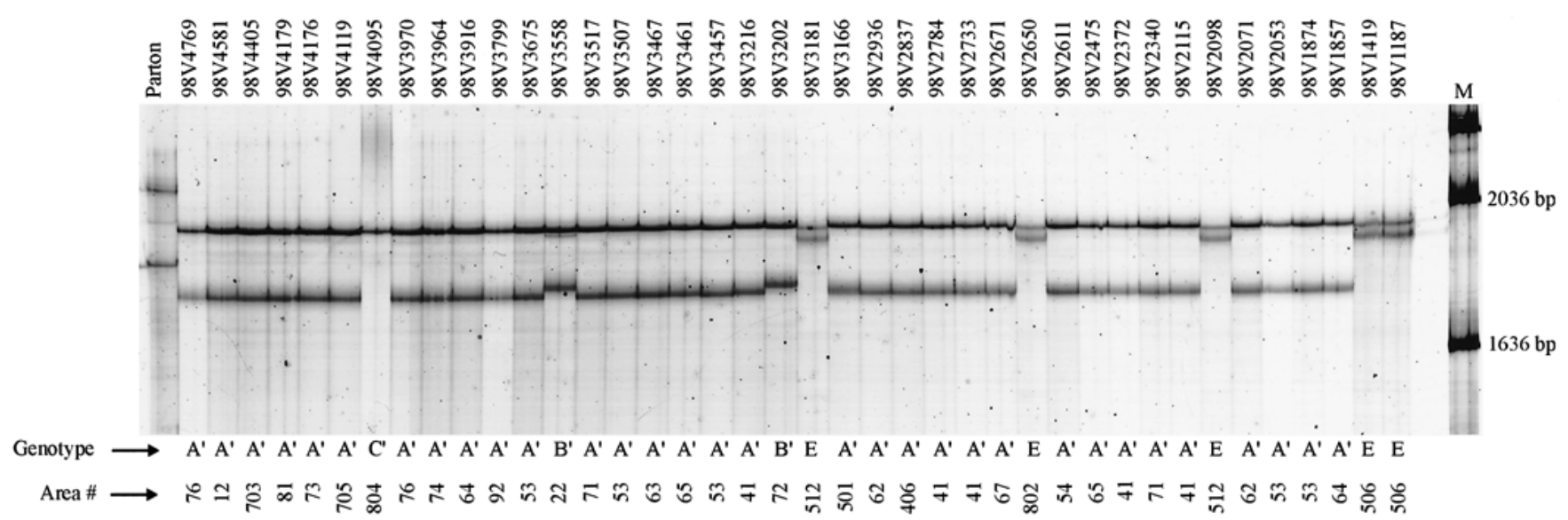

FIGURE 2. Single-strand conformation polymorphism analysis of all St. Louis encephalitis (SLE) isolates made during 1998 in Harris County. Top row: $\mathrm{M}=$ molecular weight markers (non-denatured, double-stranded DNA). Numbers 98V1187-98V4769 = all SLE isolates from 1998. Parton $=$ prototype strain from St. Louis, Missouri. Bottom row: Genotype: genotypes were assigned consecutive letters based on pattern of migration in gel. The Parton strain was not assigned a genotype. Area number $=$ the area from which each isolate originated, corresponding to the area locations in Figure 1.

fragments of up to 400 nucleotide bases in length. Occasional samples gave multiple bands in the SSCP analyses. The presence of multiple bands on the gels indicated that several different conformations were formed when the samples were cooled during the SSCP procedure. They did not affect the genotype assigned to each sample.

In any single year, one or two genotypes of the virus dominated, with the remaining genotypes occurring less frequently. Two different mechanisms may be responsible for this observation. First, the predominant genotypes may represent strains of the virus that are more virulent (causing higher viremias in birds and infecting more vector mosquitoes). These phenotypic characteristics would allow for increased transmission of such genotypes. A second possibility is that the minor genotypes may represent variants that have recently evolved from the major genotypes. Thus the presence of multiple genetic types of the virus could indicate that SLE virus in the Harris County area may be evolving fairly rapidly; or several lineages have been co-circulating for a long time. Alternatively, new strains of the virus may be imported into this area from other endemic areas in the southern United States, Central, or South America. However, the epidemiological pattern of SLE in Houston is consistent with endemic maintenance of the virus. The presence of one stable genotype (type E) is also supportive of local maintenance of the virus.

The number of SSCP genotypes was not related to the total number of mosquito pools tested (coefficient $=0.05, P$ $=0.83$ ). This supports the hypothesis that in certain years, genetic variation of the virus may occur despite a relatively low amount of viral transmission in the mosquito population. The number of SSCP genotypes obtained each year was positively correlated to the total number of isolates obtained each year (coefficient $=0.53, P=0.05$ ). This indicates that the genetic variation seen in some years may have simply been due to the large number of isolates obtained.

In this study, first passage virus material was used for all analyses. This greatly reduced the potential for genetic changes that may occur during passage in the laboratory, allowing the current study to more closely reflect the genetic variation that occurs naturally in the field.

The geographic distribution of genotypes within the county varied from year to year. In 1986, the earliest SLE activity in Harris County occurred in Baytown, where virus was isolated almost a month before any activity was noted in Houston. This was also the first time since surveillance began, that SLE activity occurred in Baytown. During this year, genotype A virus was found only in Baytown and northeast Harris County. A second genotype of the virus, genotype D, was isolated in Baytown as well as central Houston. The D genotype viruses isolated in Baytown were isolated one month prior to those isolated in Houston.

The isolates from 1989 did not show extensive genetic variability; two genotypes of the virus were seen, and all of these isolates were from the eastern half of Houston, in the central area of the county. In 1990, Harris County experienced considerable SLE activity (44 isolates; 24 human cases), and SLE virus was isolated from widespread areas. Four genotypes of the virus predominated: types $\mathrm{G}, \mathrm{H}$, and $\mathrm{J}$ were found in Houston, while type I was found only in Baytown. During 1990, most of the genotypes were found in limited geographic areas. Genotypes $\mathrm{G}$ and $\mathrm{H}$ were restricted to east and central Houston. Interestingly, genotype $\mathbf{J}$ was widely distributed, found in the southeast, north, northwest, and southwest areas of the county. Unlike the previous year in which SLE was found in Baytown (1986), during 1990, the genotype found in Baytown (genotype I) was restricted to this area.

In 1991, 89 isolates of SLE virus were made in Harris County; SSCP analyses revealed that six different genotypes of the virus were circulating during that year. As in the previous year, a single genotype (type $\mathrm{N}$ ) predominated; this virus was also widely dispersed compared to the other isolates. The $\mathrm{N}$ genotype was found in every location in Houston and also dispersed to all areas surrounding Houston. The remaining genotypes were found in only limited areas, with genotype $\mathrm{O}$ primarily found in the south part of Houston.

In 1992, 65 isolates of SLE virus were made; SSCP anal- 

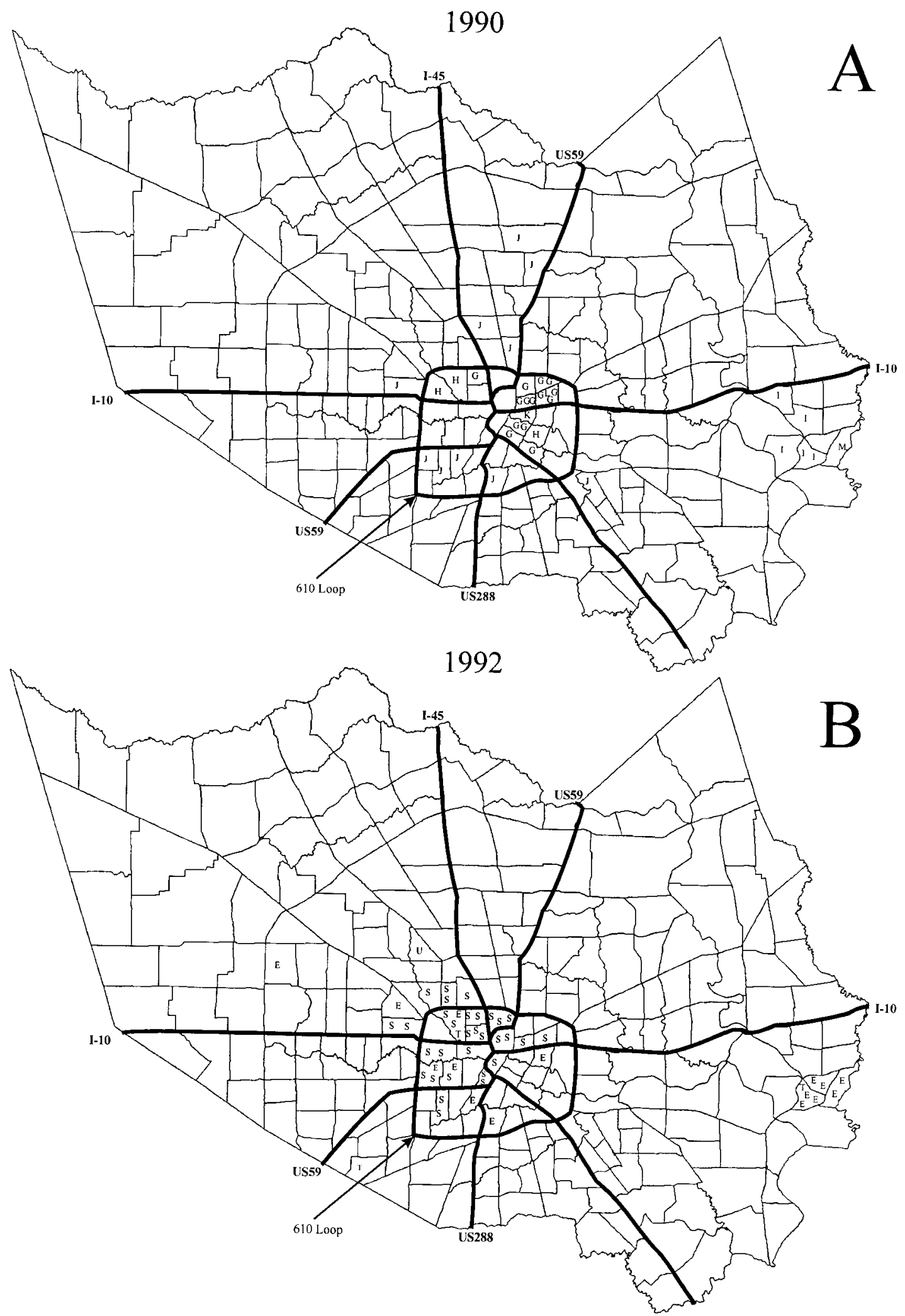

FIGURE 3. Geographic distribution of genotypes during years with differing patterns of transmission. Genotypes defined by single-strand conformation polymorphism analyses were mapped to the area where the isolate originated. A. 1990 isolates; B. 1992 isolates. In 1990, the genotypes were geographically restricted, while in 1992, widespread distribution of some genotypes was seen. 


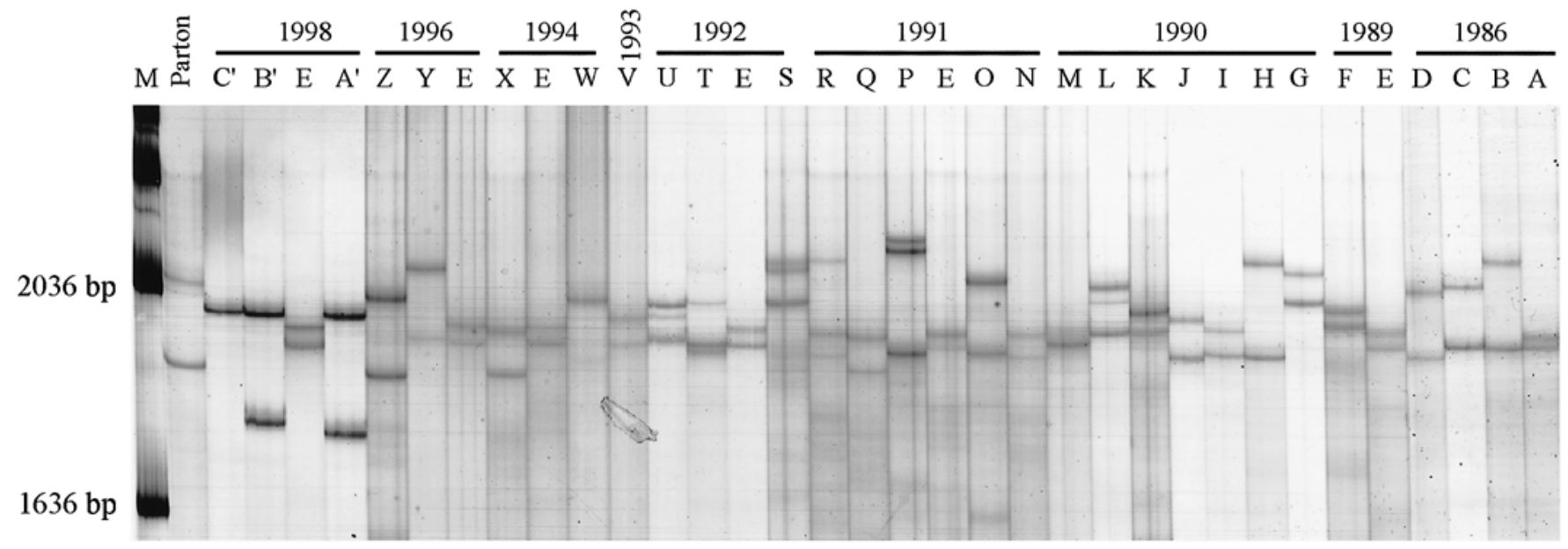

FIGURE 4. Temporal distribution of genotypes. Single-stranged conformation polymorphism analysis of all 29 genotypes from 1986, 1989, 1990, 1991, 1992, 1993, 1996, and 1998. Top row: M = molecular weight markers; Parton = prototype strain from St. Louis, Missouri. Remaining columns contain one of each genotype from each year, indicated by the letter above each column.

ysis indicated that four genotypes of the virus were circulating, and two of these prevailed. There was no geographic correlation between genotypes in 1992; genotype $\mathrm{E}$ was present in Baytown, and also in central and northwest Houston. In 1993, fewer isolates were made (a total of 35) and of these, 16 were analyzed by SSCP. All were of a single genotype, type A. This virus was also found widely dispersed throughout Harris County.

In 1994, 38 isolates of SLE virus were made, 36 of these were tested by SSCP; three genotypes of the virus were identified by SSCP. Genotype W was the predominant genotype, and was also the most widely distributed. In 1994, there was a remarkable restriction of geographic location of each genotype. Genotype W was found in central Houston, while genotype E was restricted to southeast Houston. The distinct separation of genotypes in these years indicates that transport of the virus across larger geographic areas did not occur in 1994.

The restriction of genotypes to specific areas in some years implies that the virus is circulating in small foci of transmission. During these times, it is likely that mosquitoes and/or birds that are infected with the virus do not travel between these areas. In other years, genotypes were widely distributed. The widespread distribution of one genotype indicates that these viruses are occasionally transported across larger geographic areas during these years. The SSCP analyses demonstrating geographic restriction of certain genotypes are supportive of previous observations that transmission of SLE in Harris County tends to be focal in some years, while in other years, widespread activity is seen. Thus,

TABLE 4

Summary of geographic locations of genotype E

\begin{tabular}{cl}
\hline Year & Geographic locations of genotype E \\
\hline 1989 & Central \\
1991 & Central \\
1992 & Central, Baytown, Northwest \\
1994 & Central, Southeast, Northwest \\
1998 & Southeast, Northwest \\
\hline
\end{tabular}

the differing patterns of genotype distributions in various years correlates with the pattern of SLE virus activity; in some years transmission is focal, ${ }^{7}$ while in other years, transmission is widespread. ${ }^{2,59}$ When widespread transmission occurs, it is likely that the virus is disseminated by the movement of the bird hosts of the virus-house sparrows. Large flocks of these birds disseminate throughout the city. ${ }^{10}$

Previous studies of SLE virus from the United States, Central, and South America showed considerable genetic variation among the isolates. These studies also indicated that epidemic strains are genetically different from endemic strains. ${ }^{12}$ Harris County has a history of both epidemic and endemic transmission of SLE. Significant differences in incidence, and case fatality rates have been observed between different epidemics; these differences may be due to strain differences among the SLE virus that circulates in Harris County. The results of this study indicate that SLE isolates in Harris County are genetically diverse, and strain variation may account for some of the differing epidemiological patterns that occur in Harris County. However, no single genotype could be identified that was associated with epidemic transmission years. Future studies of SLE in Harris County will include phenotypic analysis of various genetic strains, and nucleotide sequencing and phylogenetic analyses. Phenotype analyses will provide information to determine whether the distinct genotypes represent phenotypic variants that differ in biological characteristics that may impact transmission and disease potential. Phenotypes to be assessed include mouse neurovirulence, ability to cause high viremia in birds, and the efficiency of oral infection of vector mosquitoes. Nucleotide sequencing and phylogenetic analyses should also reveal the extent of genetic variation among these SLE strains, and whether or not amino acid changes that may result in biological differences have occurred. Phylogenetic analyses may also reveal whether any of the genotypes represent new strains of the virus which have occasionally been introduced into Harris County.

Acknowledgments: We thank Kyle Flatt, Stefan Nawrocki, and Taweesak Wuithiranyagool (Harris County Mosquito Control Division) 
for collection, identification, and processing of mosquitoes for virus isolation. Nicole Nordoff University of Texas Medical Branch (UTMB) provided excellent technical assistance with SSCP analyses. We thank Dr. Daniel Freeman of the Office of Biostatistics at UTMB for assistance with statistical analyses.

Financial support: This work was supported by Public Health Service grant \# AI10984 and from the National Institute of Allergy and Infectious Disease and by the John Sealy Memorial Endowment Fund for Biomedical Research at UTMB.

Authors' addresses: Laura Chandler, WHO Collaborating Center for Tropical Diseases and Clinical Microbiology Division, Room 5.114 McCullough Building, University of Texas Medical Branch, Galveston, Texas 77555-0740. Telephone: 409-747-1424; FAX: 409772-5683. Ray Parsons and Yvonne Randle, Harris County Mosquito Control Division, 3330 Old Spanish Trail, Building D, Houston, Texas 77021-4795.

Reprint requests: Laura Chandler, Ph.D. Clinical Microbiology Division, Room 5.114 McCullough Building, University of Texas Medical Branch, Galveston, Texas 77555-0740; E-mail: Laura.Chandler@ utmb.edu; Telephone: 409-747-1424; FAX: 409-772-5683

\section{REFERENCES}

1. Tsai T and Mitchell CJ, 1988. St. Louis encephalitis. Monath, TP, ed. The Arboviruses: Epidemiology and Ecology Vol. IV. Boca Raton, FL: CRC Press, 113-143.

2. Luby JP, 1979. St. Louis encephalitis. Epidemiol Revs 1: 5573

3. Hopkins CC, Hollinger FB, Johnson RF, Dewlett HJ, Newhouse VF, Chamberlan RW, 1975. The epidemiology of St. Louis encephalitis in Dallas, Texas, 1966. Am J Epidemiol 102: 115.

4. Williams KH, Hollinger FB, Metzger WR, Hopkins CC, Chamberlain RW, 1975. The epidemiology of St. Louis encephalitis in Corpus Christi, Texas, 1966. Am J Epidemiol 102: 16-24.

5. Luby JP, Miller G, Gardner P, Pigford CA, Henderson BE, Eddins D, 1967. The epidemiology of St. Louis encephalitis in Houston, Texas, 1964. Am J Epidemiol 86: 584-597.

6. Tsai TF, Canfield MA, Reed CM, Flannery VL, Sullivan KH, Reeve GR, Bailey RE, Poland JD, 1988. Epidemiological as- pects of a St. Louis encephalitis outbreak in Harris County, Texas, 1986. J Infect Dis 157: 351-356.

7. Cooperative Study Group, 1965. Epidemic St. Louis encephalitis in Houston, 1964. A cooperative study. JAMA 193: 133140.

8. Phillips CA, Melnick JL, 1965. Community infection with St. Louis encephalitis virus. JAMA 193: 107-111.

9. Bell RL, Christensen B, Holguin A, Smith O, 1981. St. Louis encephalitis: a comparison of two epidemics in Harris County, Texas. Am J Publ Health 71: 168-170.

10. Lord RD, Work TH, Coleman PH, Johnston JGJ, 1973. Virological studies of avian hosts in the Houston epidemic of St. Louis encephalitis, 1964. Am J Trop Med Hyg 22: 662-671.

11. Bowen GS, Monath TP, Kemp GE, Kerschner JH, Kirk LJ, 1980. Geographic variation among St. Louis encephalitis virus strains in the viremic responses of avian hosts. Am J Trop Med Hyg 29: 1411-1419.

12. Trent DW, Monath TP, Bowen GS, Vorndam AV, Cropp CB, Kemp GE, 1980. Variation among strains of St. Louis encephalitis virus: basis for a genetic, pathogenetic, and epidemiologic classification. Ann NY Acad Sci 354: 219-237.

13. Monath TP, Cropp B, Bowen GS, Kemp GE, Mitchell CJ, Gardner JJ, 1980. Variation in virulence for mice and rhesus monkeys among St. Louis encephalitis virus strains of different origin. Am J Trop Med Hyg 29: 948-962.

14. Kramer LD, Presser SB, Hardy JL, Jackson AO, 1997. Genotypic and phenotypic variation of selected Saint Louis encephalitis viral strains isolated in California. Am J Trop Med Hyg 57: 222-229.

15. Trent DW, Grant JA, Vorndam AV, Monath TP, 1981. Genetic heterogeneity among Saint Louis encephalitis virus isolates of different geographic origin. Virology 114: 319-332.

16. Nawrocki SJ, Randle YH, Vodkin MH, Siegel JP, Novak RJ, 1996. Evaluation of a reverse transcriptase-polymerase chain reaction assay for detecting St. Louis encephalitis virus using field-collected mosquitoes (Diptera: Culicidae). J Med Entomol 33: 123-127.

17. Tsai TF, Bolin RA, Montoya M, Bailey RE, Francy DB, Jozan M, Roehrig JT, 1987. Detection of St. Louis encephalitis virus antigen in mosquitoes by capture enzyme immunoassay. $J$ Clin Microbiol 25: 370-376.

18. Chandler LJ, Nordoff NN, 1999. Identification of genetic variation among St. Louis encephalitis virus isolates, using singlestrand conformation polymorphism analysis. J Virol Meth 80(2): 169-178. 